\title{
Shear stress regulated uptake of liposome-decorated microgels coated with a poly(dopamine) shell
}

\author{
York-Durán, María José; Ek, Pramod Kumar; Gallardo, Maria Godoy; Hosta-Rigau, Leticia
}

Published in:

Colloids and Surfaces B: Biointerfaces

Link to article, DOI:

10.1016/j.colsurfb.2018.07.031

Publication date:

2018

Document Version

Peer reviewed version

Link back to DTU Orbit

Citation (APA):

York-Durán, M. J., Ek, P. K., Gallardo, M. G., \& Hosta-Rigau, L. (2018). Shear stress regulated uptake of liposome-decorated microgels coated with a poly(dopamine) shell. Colloids and Surfaces B: Biointerfaces, 171, 427-436. https://doi.org/10.1016/j.colsurfb.2018.07.031

\section{General rights}

Copyright and moral rights for the publications made accessible in the public portal are retained by the authors and/or other copyright owners and it is a condition of accessing publications that users recognise and abide by the legal requirements associated with these rights.

- Users may download and print one copy of any publication from the public portal for the purpose of private study or research.

- You may not further distribute the material or use it for any profit-making activity or commercial gain

- You may freely distribute the URL identifying the publication in the public portal 


\section{Accepted Manuscript}

Title: Shear stress regulated uptake of liposome-decorated microgels coated with a poly(dopamine) shell

Authors: Maria Jose York-Duran, Pramod Kumar Ek, Maria Godoy-Gallardo, Leticia Hosta-Rigau

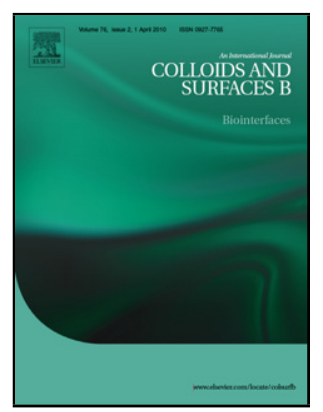

PII:

S0927-7765(18)30478-8

DOI: https://doi.org/10.1016/j.colsurfb.2018.07.031

Reference: COLSUB 9487

To appear in: $\quad$ Colloids and Surfaces B: Biointerfaces

Received date: $\quad 28-5-2018$

Revised date: $\quad 12-7-2018$

Accepted date: $\quad$ 16-7-2018

Please cite this article as: York-Duran MJ, Ek PK, Godoy-Gallardo M, HostaRigau L, Shear stress regulated uptake of liposome-decorated microgels coated with a poly(dopamine) shell, Colloids and Surfaces B: Biointerfaces (2018), https://doi.org/10.1016/j.colsurfb.2018.07.031

This is a PDF file of an unedited manuscript that has been accepted for publication. As a service to our customers we are providing this early version of the manuscript. The manuscript will undergo copyediting, typesetting, and review of the resulting proof before it is published in its final form. Please note that during the production process errors may be discovered which could affect the content, and all legal disclaimers that apply to the journal pertain. 


\section{Shear stress regulated uptake of liposome-decorated}

\section{microgels coated with a poly(dopamine) shell}

Maria Jose York-Duran ${ }^{a}$, Pramod Kumar Ek ${ }^{a}$, Maria Godoy-Gallardo ${ }^{a}$ and Leticia HostaRigau $* a^{* a}$

${ }^{a}$ Department of Micro- and Nanotechnology, Center for Nanomedicine and Theranostics, DTU Nanotech, Technical University of Denmark, Building 423, 2800 Lyngby, Denmark.

${ }^{*}$ Corresponding author.

E-mail address: leri@nanotech.dtu.dk (L. Hosta-Rigau)

\section{Graphical abstract}
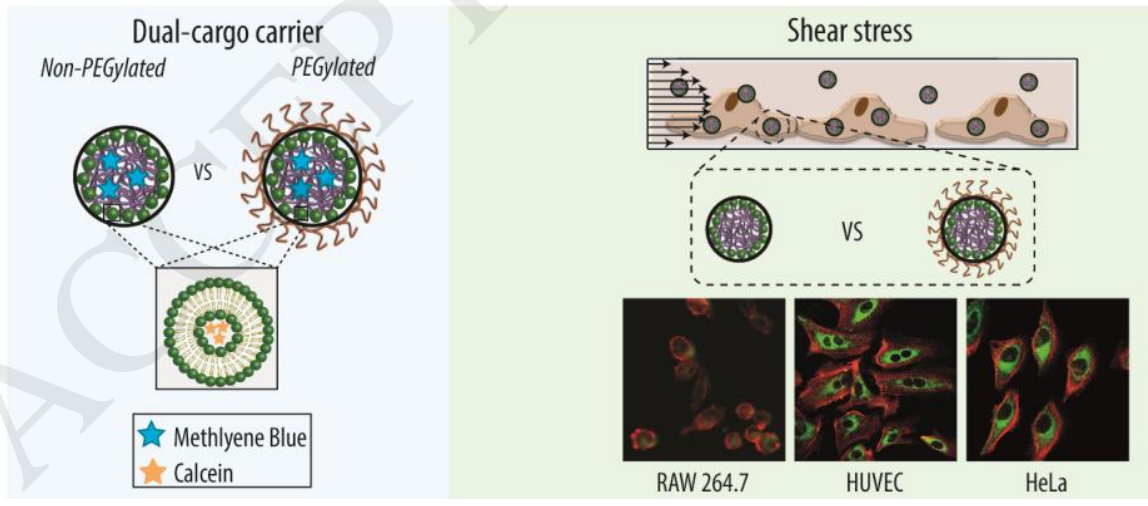

\section{HIGHLIGHTS}

- Multicompartment carrier with different release kinetics of model compounds

- Stealth properties of PEGylated multicompartment carrier upon protein exposure 
- Cellular uptake and PEGylation efficacy in cells regulated by shear stress

- Different cellular uptake pathways activated upon shear stress exposure

ABSTRACT: Advanced multicompartment drug delivery platforms ensure the co-localization of several drugs within the same carrier, thus making it possible to achieve a more effective and safe therapeutic outcome. Herein, we report a novel multicompartment architecture by combining two intrinsically different systems, i.e., polymeric microgels and liposomes, with the aim to achieve different release kinetics for model compounds. We assemble poly $(N-$ isopropylacrylamide-co-acrylic acid) microgels decorated with liposomes which are subsequently coated with a protective poly(dopamine) shell and a poly(ethylene glycol) (PEG) layer. Since any intravenous administered drug delivery vehicle will get in contact with the dynamics of the blood flow, we evaluate the stealth properties of this novel multicompartment carrier towards protein adsorption and cellular uptake by three relevant cell lines (macrophages, endothelial and cancer cells) under physiological shear stress conditions. Our results demonstrate less protein adsorption for the PEGylated carriers and differences in the extent of internalized carriers depending on the presence of a PEG coating, the studied cell line and the intensity of the applied shear stress. Additionally, we demonstrate that, for all three tested cell lines, shear stress results in the activation of different cell entry pathways as compared to static conditions. All in all, we report a thorough study about the effect of shear stress on the cell association/uptake with a novel multicompartment carrier. 
KEYWORDS: Drug release, cell uptake pathway, liposomes, microgels, multicompartment carriers, shear stress

\section{INTRODUCTION}

The construction of multicompartment architectures is an increasingly growing area, since, multicompartment carriers will allow for the encapsulation and subsequent delivery of several (incompatible) therapeutic molecules in a single vehicle.[1,2] Multicompartment carriers guarantee co-localization of different drugs, which can be of utmost importance to achieve the desired therapeutic outcome. If administered separately, attaining a homogeneous spatial and temporal co-delivery at the target site is highly unlikely due to the potential different pharmacokinetics and pharmacodynamics of the different therapeutic compounds.

A number of multicompartment carriers have been reported to date,[1,3] being the most thoroughly studied liposomes-in-liposomes,[4] polymersomes-in-polymersomes[5] and capsosomes,[6] which consist of liposomes entrapped within a polymeric carrier shell. However, all these systems have a common denominator: all the sub-compartments are made of the same nature, which makes the controlled tandem release of cargo challenging. Herein, to combine two inherently different systems with intrinsically different release kinetics, we report a novel multicompartment carrier consisting of a $\operatorname{poly}(\mathrm{N}$-isopropyalacrylamide-co-acrylic acid) (P(NIPAM-co-AAc)) microgel (MG) core decorated with liposomes and further coated with a protective poly(dopamine) (PDA) shell (Fig. 1). P(NIPAM-co-AAc) MG have been the material of choice due to their straight forward preparation, because they can be loaded with both hydrophilic and hydrophobic compounds and they can also be designed to be biodegradable by the right choice of the cross-linker.[7] 
Since P(NIPAM-co-AAc) MG exhibit a fast release profile due to their large pore sizes,[8] aiming to achieve a slower release profile, liposomes were chosen as the second type of compartments. Liposomes have attracted considerable attention as drug carriers since they are biocompatible, well suited to encapsulate both hydrophilic and hydrophobic compounds and their compositions can be easily tailored to modify surface and charge.[9] However, since liposomes possess low in vivo stability, several surface coatings have been reported to enhance their stability.[10] Amongst them, the self-polymerization of dopamine (DA) into PDA has been used as a coating for liposomes rendering them with increased stability.[11] PDA also allows for post-functionalization by means of its ability to react in a straight forward manner with thiols and amines.[11]

To maximize drug delivery to tumours, carrier vehicles need to circulate with a long half-life until they reach the target tumour. This effect is usually achieved by decorating the carriers surface with poly(ethylene glycol) (PEG).[12] PEGylation of our multicompartment carrier is easily achievable by reaction of the PDA coating with the amino groups of the copolymer polyL-lysine-graft-PEG (PLL-g-PEG) (Fig. 1). 


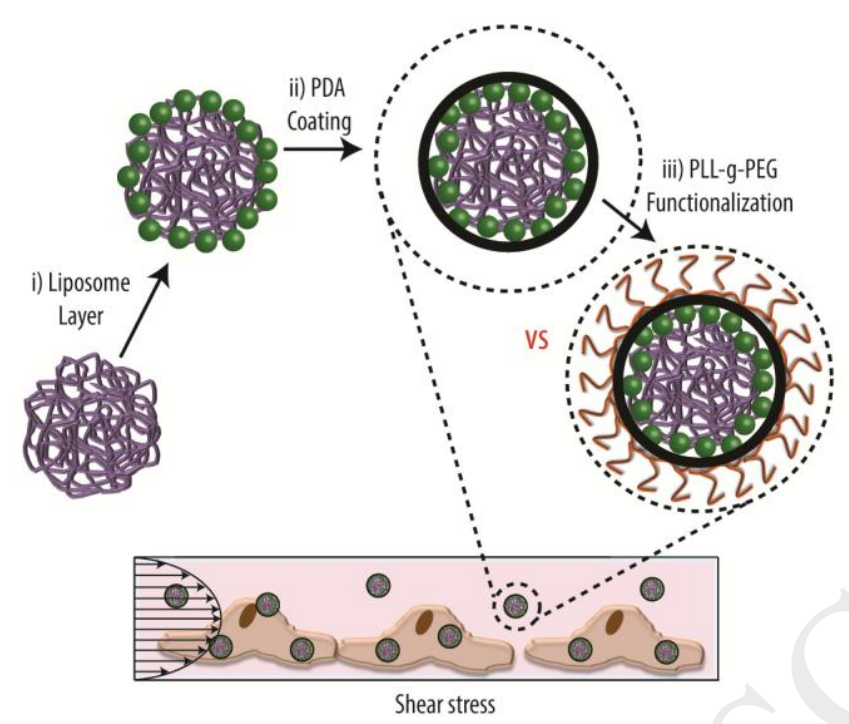

Fig.1. A microgel core is decorated with a liposome layer (i), followed by the deposition of a polydopamine (PDA) coating (ii). Finally, the surface of the carrier is functionalized with polyL-lysine-graft-PEG (PLL-g-PEG) (iii). Inset: Evaluation of the PEGylation effect by RAW 264.7 (macrophages), HUVEC (endothelial) and HeLa (cervix cancer) cells under shear stress.

From a different note, upon intravenous injection, drug delivery vehicles are exposed to the dynamics of the circulating blood flow but also of the interstitial fluids and vascular microenvironment in tumours, when targeting cancer is the aim. Both the blood flow and the interstitial fluids in the tumour microenvironment generate mechanical forces such as shear stress. Although it has been previously shown that shear stress can affect the carriers cytotoxicity,[13] PEGylation efficiency[11] or the carriers association/interaction with cells,[14] including shear stress in in vitro set-ups is still rarely seen in literature. This fact could partially explain the poor transition from in vitro to preclinical studies.[13] Microfluidic devices are great tools to generate a relevant physiological dynamic environment to assess the performance of the developed carrier.[15] They offer the possibility to closely studying the interactions between drug delivery carriers and biological systems by accurately controlling the fluidic conditions 
resulting in improved in vitro set-ups.[16] Their relevance has been demonstrated by the in vivo validation of the findings previously observed using microfluidic devices.[17]

Herein, aiming to address these challenges, we i) assemble P(NIPAM-coAAc)/liposomes/PDA carriers; ii) functionalize them with PLL-g-PEG to obtain a low-fouling effect; iii) assess the PEGylation efficiency in terms of protein adsorption; iv) evaluate the release profiles of two model compounds encapsulated in independent compartments of the carriers; v) assess the interaction of the multicompartment carriers with three different cell lines (i.e., endothelial cells, macrophages and cancer cells) in the presence of shear stress; and, finally, vi) evaluate the influence of shear stress in the cell internalization pathway of the multicompartment carriers.

\section{METHODS}

\section{Assembly and characterization of the multicompartment carriers}

P(NIPAM-co-AAc) $\quad \mathrm{MG}$ and liposomes (L) were assembled and characterized as described in the Supplementary Material. For the preparation of non-PEGylated carriers (MG/L/PDA), a suspension of $958 \mu \mathrm{g}$ MG in Tris 1 (10 mM Tris, pH 8.5) was incubated with L (0.25 mg lipids) for $1.5 \mathrm{~h}$. Next, the suspension was incubated for $16 \mathrm{~h}$ in a DA solution $\left(1 \mathrm{mg} \mathrm{mL}^{-1}\right.$ in Tris 1$)$ followed by $2 \times$ washing cycles in Tris $2(10 \mathrm{mM}$ Tris and $150 \mathrm{mM} \mathrm{NaCl}, \mathrm{pH} 7.4$ ). For the PEGylated carriers (MG/L/PDA/PEG), the MG/L/PDA assemblies were incubated with PLL-g-PEG $\left(1 \mathrm{mg} \mathrm{mL}^{-1}\right.$ in Tris 1$)$ for $1 \mathrm{~h}$ and washed $2 \times$ in Tris 2 to stop the DA self-polymerization. 
Differential interference contrast (DIC) and fluorescence microscopy. The samples were imaged with an Olympus Inverted IX83 microscope equipped with a 60x oil-immersion objective.

Size distribution. The diameters of the carriers were determined by measuring at least 200 particles in five independent DIC images using an imaging software (Image J).

Zeta $(\zeta)$-potential. The $\zeta$-potential of all the assemblies was measured in Milli- $Q$ water using a ZetaPALS ろ-potential analyzer (Brookhaven Instruments Corporation, Holtsville, NY, USA).

Quartz crystal microbalance with dissipation (QCM-D) monitoring. The deposition of the different layers on a silica crystal (QSX300, Q-sense) was monitored using a Q-sense E1 instrument (Biolin Scientific, Sweden). For details see Supplementary Material. Briefly, first, a poly-L-lysine (PLL) solution $\left(1 \mathrm{mg} \mathrm{mL}^{-1}\right.$ in Tris 1$)$ was loaded in the flow module reaching surface saturation. After washing the PLL excess, a suspension of $350 \mathrm{~nm}$-sized MG (7.2 mg $\mathrm{mL}^{-1}$ in Tris 1) was loaded reaching surface saturation and followed by a washing step. The L were then loaded also reaching surface saturation. Upon washing, a DA solution $\left(1 \mathrm{mg} \mathrm{mL} \mathrm{m}^{-1}\right.$ in Tris 1) was loaded for $1 \mathrm{~h}$. Finally, a PLL-g-PEG solution (1 mg mL $\mathrm{m}^{-1}$ in Tris 1$)$ was also loaded reaching surface saturation. Dissipation and normalized frequency values using the third harmonic are reported.

\section{Protein adsorption onto multicompartment carriers}

A suspension of MG/L/PDA or MG/L/PDA/PEG $(0.47 \mathrm{mg}$ in $0.2 \mathrm{~mL})$ was incubated at $37{ }^{\circ} \mathrm{C}$ for $4 \mathrm{~h}$ in FITC-labelled immunoglobulin G (IgG-FITC) or bovine serum albumin (BSA-FITC) solutions $\left(0.5 \mathrm{mg} \mathrm{mL}^{-1}\right.$ in PBS) and washed $3 \times$ in PBS. The fluorescence intensity readings of the bound proteins onto the carriers were evaluated by flow cytometry (BD Biosciences, Sparks, MD, USA). For protein adsorption under the presence of shear stress $(\tau)$, we employed the same 
concentration of protein-to-carrier as in static conditions. In particular, syringes containing 17.6 mg of carriers suspended in a $0.5 \mathrm{mg} \mathrm{mL}^{-1}$ protein solution in PBS $(7.5 \mathrm{~mL})$ were connected to a chamber ( $\mu$-slide VI ${ }^{0.4}$, tissue culture treated, Ibidi GmbH. Munich, Germany) applying two

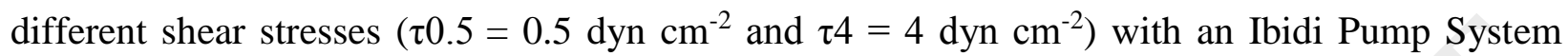
(Ibidi GmbH, Munich, Germany). At least 20000 events were analyzed in two independent experiments.

\section{Release kinetics}

Methylene blue (MB) release kinetics. $\mathrm{MB}$ was loaded into $\mathrm{MG}$ rendering $\mathrm{MG}^{\mathrm{MB}}$. Next, suspensions containing $56.2 \mathrm{mg} \mathrm{mL}^{-1}$ of $\mathrm{MG}^{\mathrm{MB}} / \mathrm{L} / \mathrm{PDA}$ or $\mathrm{MG}^{\mathrm{MB}} / \mathrm{L} / \mathrm{PDA} / \mathrm{PEG}$ carriers in Tris 2 were incubated at $37{ }^{\circ} \mathrm{C}$. At different time-points, the absorbance of the supernatants was measured at $664 \mathrm{~nm}$ employing a Tecan Spark multimode plate reader. Carriers without MB were employed as controls. The results were normalized to the absorbance (A) at the maximum incubation time: Release of $\mathrm{MB}(\%)=\left(\mathrm{A}_{\mathrm{t}}-\mathrm{A}_{0} / \mathrm{A}_{\infty}-\mathrm{A}_{0}\right) \times 100$. Being $\mathrm{A}_{t}: \mathrm{A}$ at different time points; $\mathrm{A}_{0}$ : A at time zero; $\mathrm{A}_{\infty}: \mathrm{A}$ at maximum incubation time. At least two independent experiments were carried out.

Calcein (Cal) release kinetics. Cal was loaded into $\mathrm{L}$ rendering $\mathrm{L}^{\mathrm{Cal}}$. Next, suspensions containing $28.1 \mathrm{mg} \mathrm{mL}^{-1}$ of $\mathrm{MG} / \mathrm{L}^{\mathrm{Cal}} / \mathrm{PDA}$ or $\mathrm{MG} / \mathrm{L}^{\mathrm{Cal}} / \mathrm{PDA} / \mathrm{PEG}$ in Tris 2 were incubated at 37 ${ }^{\circ} \mathrm{C}$. At different time points, the fluorescence intensities of the supernatants were measured at an excitation and emission wavelengths of $485 \mathrm{~nm}$ and $535 \mathrm{~nm}$, respectively, employing a multimode plate reader (Victor3-1420 Multilabel Counter, PerkingElmer, Waltham, MA, USA). The maximum release of Cal was achieved by adding $0.1 \%$ (v/v) Triton-X. Carriers with empty L were employed as controls. The results were normalized to the fluorescence intensity (FI) after Triton-X addition: Release of Cal $(\%)=\left(\mathrm{FI}_{\mathrm{t}}-\mathrm{FI}_{0} / \mathrm{FI}_{\mathrm{TX}}-\mathrm{FI}_{0}\right) \times 100$. Being $\mathrm{FI}_{\mathrm{t}}$ : FI at different 
time points; $\mathrm{FI}_{0}$ : FI at time zero; $\mathrm{FI}_{\mathrm{TX}}$ : FI after Triton-X addition. At least two independent experiments were performed.

\section{Cell Experiments}

For details regarding cell culture procedures and the microfluidic set up see Supplementary Material (Fig. S1).

Cell association/uptake experiments. Static and dynamic conditions: The cells were exposed to a concentration of $3.7 \mathrm{ng}$ of both non-PEGylated and PEGylated carriers entrapping fluorescently labelled liposomes $\left(\mathrm{L}^{\mathrm{F}}\right)\left(\mathrm{MG} / \mathrm{L}^{\mathrm{F}} / \mathrm{PDA}\right.$ or $\left.\mathrm{MG} / \mathrm{L}^{\mathrm{F}} / \mathrm{PDA} / \mathrm{PEG}\right)$ per cell $\left(4 \mathrm{~h}, 3{ }^{\circ} \mathrm{C}\right.$, $5 \% \mathrm{CO}_{2}$ ). Upon incubation, the cells were washed and harvested from the wells for flow cytometry analysis. For dynamic conditions the applied shear stress was accurately controlled by the Ibidi Pump System.

The cellular uptake efficiency (CUE) was determined as the percentage of cells with mean fluorescence intensity higher than the auto-fluorescent level of the cells.

For fluorescence imaging, for both static and dynamic conditions: the cells were seeded either in well plates equipped with a sterile cover glass (static conditions) or in the channels of the microfluidic chamber (dynamic conditions). Upon incubation with $\mathrm{MG} / \mathrm{L} / \mathrm{PDA}$ or $\mathrm{MG} / \mathrm{L}^{\mathrm{F}} / \mathrm{PDA} / \mathrm{PEG}$, the cells were fixed with $4 \%$ PFA and the actin filaments were stained with phalloidin-TRITC. The cells were imaged using a confocal laser scanning microscope (CLSM).

Cell viability. After carrier exposure (MG/L/PDA or MG/L/PDA/PEG), the cells were incubated in a solution containing WST-8 reagent. The cell viability was assessed by monitoring the reduced WST-8 product at $450 \mathrm{~nm}$ using a multimodal plate reader. Cells without exposition to carriers and media only were used as controls. 
Cellular uptake pathway. Static and dynamic conditions: The different cells were first preincubated with the different inhibitors.[18] Next, carriers loaded with $\mathrm{L}^{\mathrm{F}}$ (MG/L/PDA or $\mathrm{MG} / \mathrm{L}^{\mathrm{F}} / \mathrm{PDA} / \mathrm{PEG}$ ) were added in the presence of the inhibitors and incubated for $4 \mathrm{~h}$ at $\tau=0$ dyn $\mathrm{cm}^{-2}(\tau 0), \tau=0.5 \mathrm{dyn}^{-2}(\tau 0.5), \tau=4 \mathrm{dyn}^{-2}(\tau 4)$ or $\tau=20 \mathrm{dyn}^{-2}(\tau 20)$. Untreated cells and cells exposed only to carriers where used as controls. Upon incubation, the cells were harvested for flow cytometry analysis.

\section{RESULTS AND DISCUSSION}

\begin{tabular}{|ll|}
\hline Abbreviation & \\
\hline P(NIPAM-co-AAc) & poly $(N$-isopropyalacrylamide-co-acrylic acid $)$ \\
\hline MG & microgel \\
\hline PDA & poly(dopamine $)$ \\
\hline DA & dopamine \\
\hline PEG & poly(ethylene glycol $)$ \\
\hline PLL-g-PEG & poly- $L$-lysine-graft-PEG \\
\hline L & liposomes \\
\hline MG/L/PDA & Non PEGylated multicompartment carriers \\
\hline MG/L/PDA/PEG & PEGylated multicompartment carriers \\
\hline PLL & poly- $L$-lysine \\
\hline IgG-FITC & FITC-labelled immunoglobulin $G$ \\
\hline BSA-FITC & FITC-labelled bovine serum albumin \\
\hline MB & methylene blue \\
\hline Cal & calcein \\
\hline MG & methylene blue-loaded microgels \\
\hline L Cal & calcein-loaded liposomes \\
\hline LF & fluorescently labelled liposomes \\
\hline
\end{tabular}

Table 1. List of the abbreviations of the systems used.

\section{Multicompartment carrier assembly and characterization}

Liposome deposition. Aiming to engineer a dual drug delivery vehicle, we adsorbed $\mathrm{L}^{\mathrm{F}}$ onto MG which bind by electrostatic interactions. $L^{F}$ and MG had a diameter of $102.8 \pm 0.6 \mathrm{~nm}$ and $740.5 \pm 17.9 \mathrm{~nm}$, respectively, and a $\zeta$-potential of $31.5 \pm 5 \mathrm{mV}$ and $-45.8 \pm 5.7 \mathrm{mV}$ 
respectively. The optimization of the amount of $\mathrm{L}^{\mathrm{F}}$ per MG was conducted by monitoring the normalized mean fluorescence intensity (nMFI) of the $\mathrm{MG} / \mathrm{L}^{\mathrm{F}}$ assembly by flow cytometry upon addition of increasing amounts of $\mathrm{L}^{\mathrm{F}}$ (expressed as $\mathrm{mg}$ of lipids) to a constant amount of MG. The results, which have been normalized to the highest amount of adsorbed $\mathrm{L}^{\mathrm{F}}$ without causing aggregation of the sample, show a linear trend between the amount of $\mathrm{L}^{\mathrm{F}}$ added and the $\mathrm{nMFI}$ (Fig. 2ai). DIC images demonstrate that the maximum $\mathrm{L}^{\mathrm{F}}$ deposition without causing aggregation was achieved when the MG were exposed to $\mathrm{L}^{\mathrm{F}}$ composed of $0.125 \mathrm{mg}$ of lipids (Fig. 2ai, inset 1 and 2). Fluorescence microscopy images which show a green fluorescent signal arising from $\mathrm{L}^{\mathrm{F}}$, also suggest the $\mathrm{L}^{\mathrm{F}}$ attachment onto the MG (Fig. 2aii and Fig. S2a).

a) i)

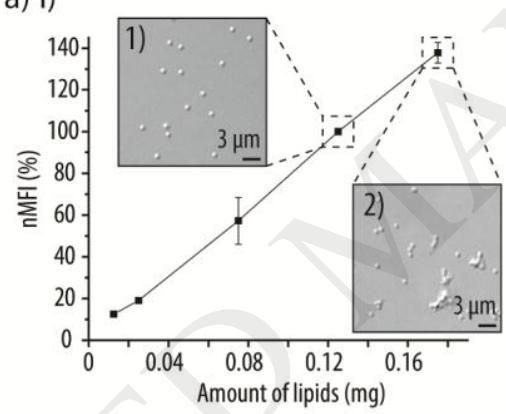

b) i)

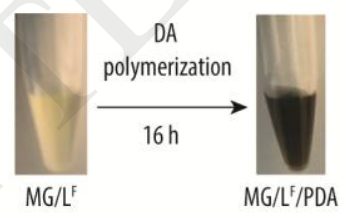

ii)

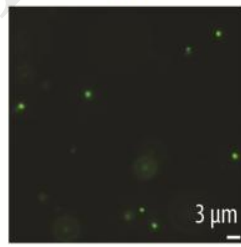

ii)

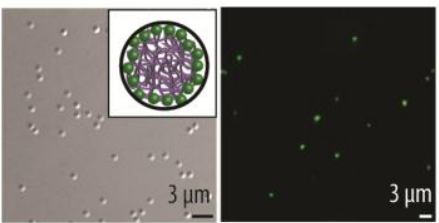

Fig.2. a) i) Normalized mean fluorescence intensity (nMFI) readings of the microgels (MG) upon incubation with fluorescently labelled liposomes $\left(\mathrm{L}^{\mathrm{F}}\right)$ (expressed as mg of lipids). Inset 1: Differential interference contrast (DIC) microscopy image of non-aggregated $\mathrm{MG} / \mathrm{L}^{\mathrm{F}}$. Inset 2: DIC microscopy image of aggregated $\mathrm{MG} / \mathrm{L}^{\mathrm{F}}$. ii) Fluorescence microscopy image of nonaggregated $\mathrm{MG} / \mathrm{L}^{\mathrm{F}}$. b) i) Deposition of a poly(dopamine) (PDA) coating by dopamine (DA) selfpolymerization onto $\mathrm{MG} / \mathrm{L}^{\mathrm{F}}$. ii) $\mathrm{DIC}$ and fluorescence microscopy images of $\mathrm{MG} / \mathrm{L}^{\mathrm{F}} / \mathrm{PDA}$. At least two independent experiments were carried out $(n=2)$. 
Prime-coating with PDA. Prior functionalization with PLL- $g$-PEG, the MG/L ${ }^{\mathrm{F}}$ assemblies were incubated with DA in Tris 1 buffer. After $16 \mathrm{~h}$ of incubation, the MG/L ${ }^{\mathrm{F}}$ suspension turned dark, indicating DA polymerization into PDA (Fig. 2bi). DIC and fluorescence microscopy images demonstrated that the $\mathrm{MG} / \mathrm{L}^{\mathrm{F}} / \mathrm{PDA}$ assemblies were non-aggregated and preserved the spherical architecture (Fig. 2bii). The $\mathrm{MG} / \mathrm{L}^{\mathrm{F}} / \mathrm{PDA}$ carriers were also imaged by scanning electron microscopy (SEM) and compared to the uncoated $\mathrm{MG} / \mathrm{L}^{\mathrm{F}}$ assemblies and to the bare MG (Fig. S2bi). No noticeable differences between the three samples were observed, indicating the absence of PDA aggregates on the MG surface. The size of the assembly was determined by measuring the diameter of the carriers employing DIC images. The results, which were plotted as a size-distribution histogram, show an increase in diameter from $\sim 750 \mathrm{~nm}$, for bare $\mathrm{MG}$, to $\sim 950$ $\mathrm{nm}$ for the $\mathrm{MG} / \mathrm{L}^{\mathrm{F}} / \mathrm{PDA}$ assemblies (Fig. S2bii). Overall, these results point towards the successful deposition of a PDA layer onto $\mathrm{L}^{\mathrm{F}}$-coated MG.

PEGylation. PDA can be functionalized in a straightforward manner due to the reactivity of its quinone groups towards amines and thiols.[10] Thus, to create PEGylated multicompartment carriers (MG/L/PDA/PEG) we functionalized the PDA outer surface with PLL-g-PEG. The functionalization of the surface was first investigated by $\zeta$-potential measurements confirming the negative charge of bare MG $(-45.8 \pm 5.7 \mathrm{mV})$. The $\mathrm{L}$ adsorption was confirmed by an increase in the $\zeta$-potential $(-35.8 \pm 6.1 \mathrm{mV}$ ) (Fig. 3ai). Upon DA polymerization into PDA, another increase in $\zeta$-potential measurement was observed $(-27.8 \pm 3.4 \mathrm{mV})$. Next, the MG/L/PDA carriers were incubated at three different concentrations of PLL- $g$-PEG (i.e., 1, 5 and $7 \mathrm{mg} \mathrm{mL}^{-1}$ ) which, in agreement with previous reports,[11] resulted in a slight decrease in $\zeta$ potential. We speculate that these minimal changes in $\zeta$-potential upon deposition of the positively charged PLL-g-PEG, could be due to the fact that most of the amino groups of PLL-g- 
PEG have reacted with the PDA quinones.[19] Since the three tested concentrations resulted in a very similar $\zeta$-potential, we selected the lowest concentration to conduct the next experiments. DIC and fluorescence microscopy images of $\mathrm{MG} / \mathrm{L}^{\mathrm{F}} / \mathrm{PDA} / \mathrm{PEG}$ assemblies demonstrate that the PEGylated carriers are non-aggregated (Fig. 3aii).

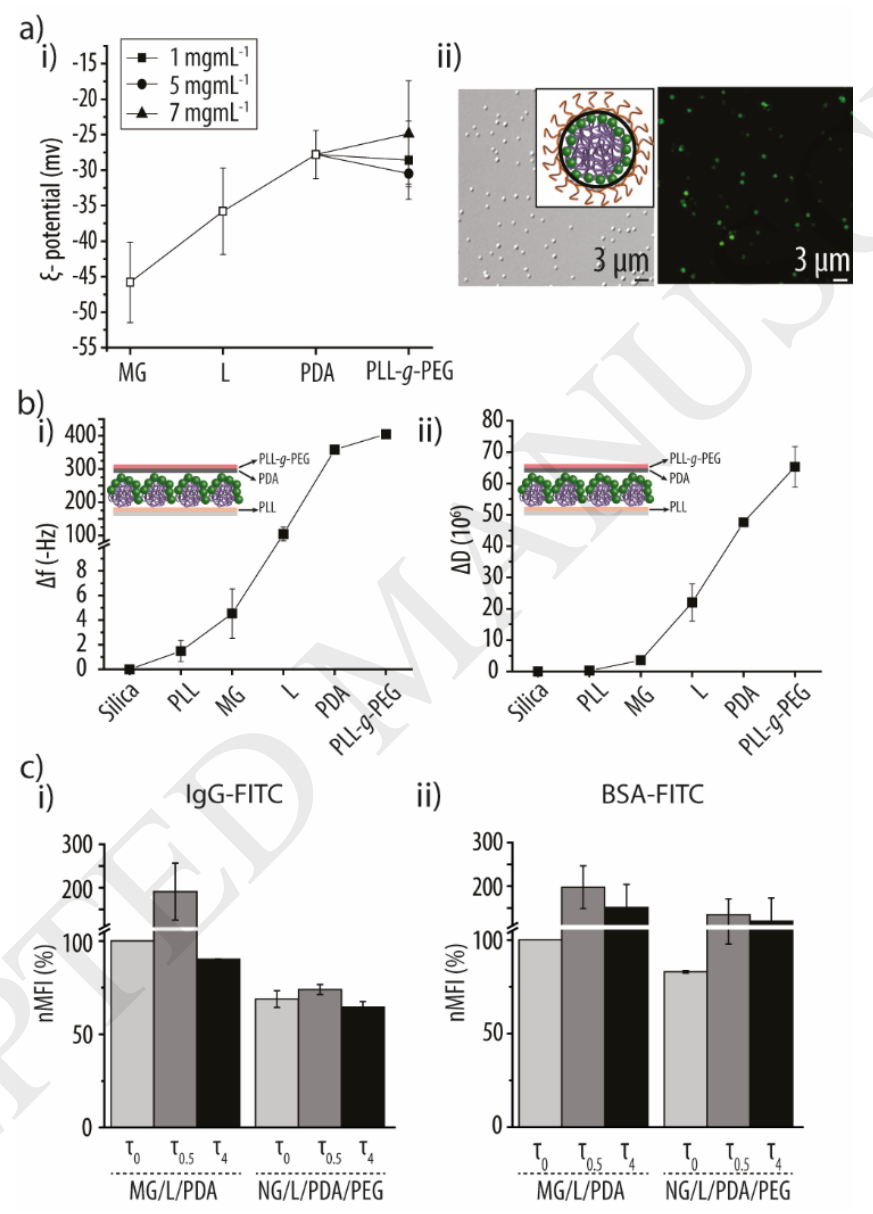

Fig.3. a) i) ל-potential measurements of microgels (MG) after adsorbing: liposomes (L), poly(dopamine) (PDA) and poly-L-lysine-graft-poly(ethylene glycol) (PLL-g-PEG). ii) Differential interference contrast and fluorescence microscopy images of PEGylated carriers entrapping fluorescently labelled $\mathrm{L}\left(\mathrm{L}^{\mathrm{F}}\right)\left(\mathrm{MG} / \mathrm{L}^{\mathrm{F}} / \mathrm{PDA} / \mathrm{PEG}\right)$. b) Frequency $(\Delta \mathrm{f})$ (i) and dissipation $(\Delta \mathrm{D})$ (ii) changes measured after each deposition step. c) Normalized mean fluorescence intensity (nMFI) readings of $\mathrm{MG} / \mathrm{L} / \mathrm{PDA}$ and $\mathrm{MG} / \mathrm{L} / \mathrm{PDA} / \mathrm{PEG}$ carriers upon incubation with IgG-FITC (i) and BSA-FITC (ii) at static $\left(\tau=0\right.$ dyn $\left.\mathrm{cm}^{-2}(\tau 0)\right)$ and shear stress 
conditions $\left(\tau=0.5 \mathrm{dyn} \mathrm{cm}^{-2}(\tau 0.5)\right.$ and $\left.\tau=4 \mathrm{dyn}_{\mathrm{cm}}^{-2}(\tau 4)\right)$. At least two independent experiments were carried out $(\mathrm{n}=2)$.

To confirm the structural integrity of the L layer and to be able to draw a stronger conclusion on the functionalization of the PDA coating, we monitored the assembly of the MG/L/PDA/PEG carriers by QCM-D (Fig. 3bi and ii). First, we deposited a positively charged polymer layer (PLL) onto a negatively charged silica sensor. The successful deposition of PLL was confirmed by measuring a change of frequency $(\Delta \mathrm{f})$ followed by the deposition of negatively charged MG. We would like to note that the MG employed to conduct the QCM-D experiments are smaller $(\sim 350 \mathrm{~nm})$ than the MG employed to assemble the multicompartment carriers $(\sim 740 \mathrm{~nm})$ due to the inherent limitations of the technique, which sensitivity is compromised when loading larger particles. The deposition of the L layer yielded both a large $\Delta \mathrm{f}$ and change in dissipation $(\Delta \mathrm{D})$, suggesting the adsorption of intact liposomes rather than a lipid bilayer.[20] To confirm that the deposition of $\mathrm{L}$ was due to the negative charge conferred by the $\mathrm{MG}$, a control experiment without MG was conducted (data not shown). Upon PDA deposition, a further increase in $\Delta \mathrm{f}$ was observed, indicating that the deposition of PDA did not displaced or ruptured the L. Finally, upon PLL-g-PEG deposition a change in $\Delta \mathrm{f}$ was also observed, suggesting successful PEGylation of the system.

The stability upon storage in PBS at $4{ }^{\circ} \mathrm{C}$ of both the PEGylated and non-PEGylated carriers in terms of aggregation was also evaluated. DIC microscopy images taken at different time points up to 14 days reveal good colloidal stability for both samples for the whole time-frame (Fig. S3).

\section{Protein adsorption}

The exposure of a drug delivery vehicle to blood leads to the accumulation of opsonins on the surface of the carrier, thus increasing its recognition and clearance by the mononuclear 
phagocyte system.[21] PEGylation of the carriers has been widely used in the drug delivery field as a strategy to shield the surface from opsonization and increase their circulation time.

$\mathrm{IgG}$ is the most abundant immunoglobulin in blood and is believed to act as a potent opsonin, while albumin is the most abundant protein in plasma. Although albumin is thought to have a dysopsonic effect, albumin can be easily replaced by other proteins with opsonic effect.[21] Since intravenously administered drug delivery vehicles will be directly exposed to the dynamic environment of the blood flow, we evaluated the PEGylation efficacy in terms of inhibition of IgG and BSA adsorption in the presence of shear stress. MG/L/PDA and MG/L/PDA/PEG were incubated with IgG-FITC and BSA-FITC at $37{ }^{\circ} \mathrm{C}$ for $4 \mathrm{~h}$ at $\tau 0$ and microvasculature shear stress conditions ( $\tau 0.5$ and $\tau 4) .[13]$ We evaluated the protein binding onto the carriers and the results, which were normalized to the protein binding to MG/L/PDA at $\tau 0$, demonstrated that PEGylation leads to a slight decrease in nMFI for both proteins at $\tau 0$ and $\tau 4$ (Fig. $3 \mathrm{ci}$ and ii). Interestingly, a far more pronounced decrease in nMFI was observed at $\tau 0.5(\sim 117 \%$ and $\sim 64 \%$ for IgG-FITC and BSA-FITC, respectively). These results indicate that, although the effect is quite limited in some of the tested conditions, PEGylation of the carrier has an effect in protein binding in all the tested settings. Fluorescence and DIC microscopy images revealed that the presence of the proteins did not affect the colloidal stability of the carriers (Fig. S4).

\section{Dual-cargo release kinetics}

While both P(NIPAM-co-AAc) MG[7] and liposomes[22] have been extensively used in the drug delivery field, little has been done regarding the combination of both systems towards the creation of a more advanced platform. Previous studies of P(NIPAM-co-AAc) MG decorated with liposomes have focused only on the control over the liposome release kinetics[23,24] while a solitary study has exploited the potential of this system as a dual drug delivery vehicle.[8] 
Since the main advantage of multicompartment systems is the possibility to co-encapsulate (incompatible) drugs in separated compartments, we encapsulated two distinguishable fluorophores, $\mathrm{MB}$ and $\mathrm{Cal}$, within the $\mathrm{MG}$ and the $\mathrm{L}$ core. The release profiles at $37{ }^{\circ} \mathrm{C}$ for $\mathrm{MB}$ and $\mathrm{Cal}$ were assessed independently for both PEGylated $\left(\mathrm{MG}^{\mathrm{MB}} / \mathrm{L} / \mathrm{PDA} / \mathrm{PEG}\right.$ and $\left.\mathrm{MG} / \mathrm{L}^{\mathrm{Cal}} / \mathrm{PDA} / \mathrm{PEG}\right)$ and non-PEGylated $\left(\mathrm{MG}^{\mathrm{MB}} / \mathrm{L} / \mathrm{PDA}\right.$ and $\left.\mathrm{MG} / \mathrm{L}^{\mathrm{Cal}} / \mathrm{PDA}\right)$ carriers. For nonPEGylated carriers and MB, the results, which have normalized to the maximum amount of MB cumulative release, show a rapid release profile for the first 7-9 $\mathrm{h}(\sim 80 \% \mathrm{MB}$ release) followed by a slow increase of the release rate (Fig. 4a). For Cal release, the results have been normalized to the Cal cumulative release upon addition of Triton $\mathrm{X}$, which was added after $24 \mathrm{~h}$ incubation to rupture the $\mathrm{L}$ and release the remaining entrapped $\mathrm{Cal}$. The $\mathrm{Cal}$ release profile started with a burst release ( $\sim 20 \%$ in $1 \mathrm{~h}$ ) followed by a slower release rate, reaching $\sim 70 \%$ release after $24 \mathrm{~h}$ (Fig. 4b). Thus, as expected, the L showed a slower release profile as compared to the MG. Since the release mechanism of molecules is dependent on both the nature of the molecule and the compartment, a fast release of $\mathrm{MB}$, which is a small hydrophilic compound, from the large pores of the MG was to be expected.[8] Since the MG are composed by a pH- and thermoresponsive polymer, the $\mathrm{MB}$ release could be potentially controlled by $\mathrm{pH}$ and temperature changes. For Cal release, which is also a small hydrophilic compound, the results are different. The release from the liposomes could potentially be controlled by temperature changes since, the fluidity of the liposome membrane, increases upon increasing the temperature.[25] It is also worth noting that, for PEGylated carriers, a general increase in the release rate was observed for both $\mathrm{MB}$ and $\mathrm{Cal}$, suggesting that the PLL-g-PEG functionalization slightly increases either the PDA or the underlying $\mathrm{L}$ permeability. 


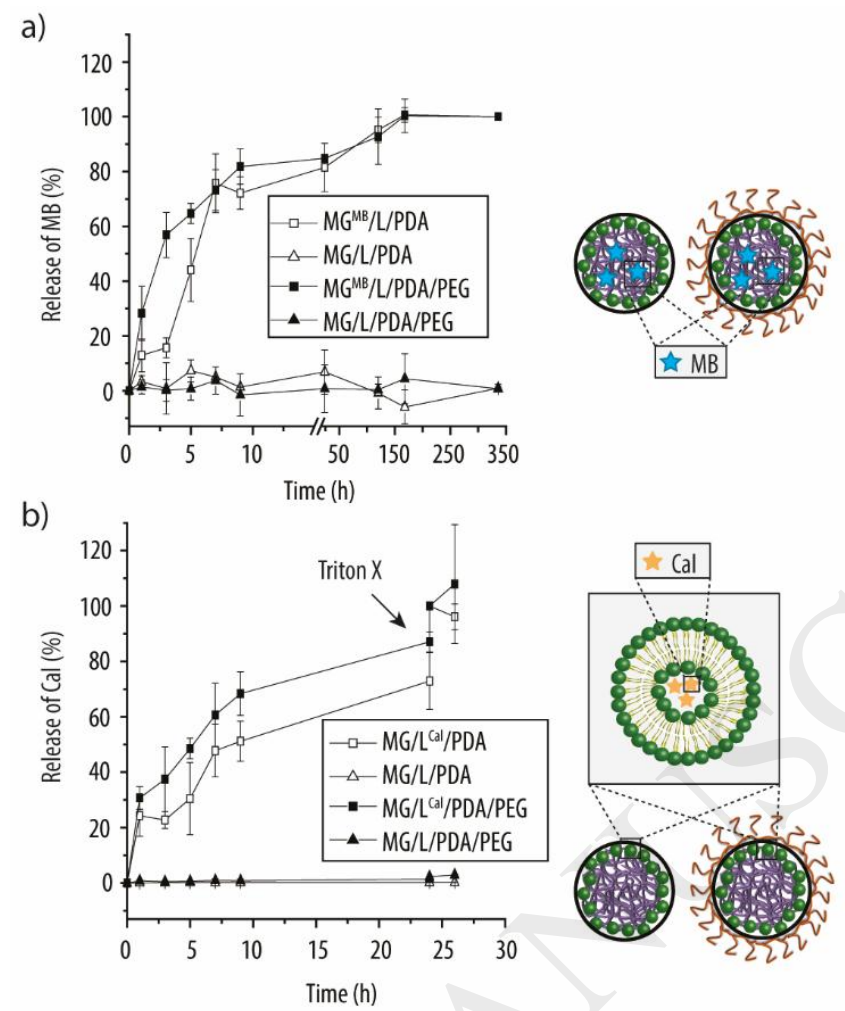

Fig.4. a) Release of methylene blue (MB) from non-PEGylated $\mathrm{MG}^{\mathrm{MB}} / \mathrm{L} / \mathrm{PDA}$ and PEGylated $\mathrm{MG}^{\mathrm{MB}} / \mathrm{L} / \mathrm{PDA} / \mathrm{PEG}$ carriers. b) Release of calcein (Cal) from non-PEGylated $\mathrm{MG} / \mathrm{L}^{\mathrm{Cal}} / \mathrm{PDA}$ and PEGylated MG/L ${ }^{\mathrm{Cal}} / \mathrm{PDA} / \mathrm{PEG}$ carriers. At least two independent experiments were carried out $(\mathrm{n}=2)$.

\section{Interaction of non-functionalized and PEGylated carriers with cells}

Next, we assessed the interaction of the carriers with three different cell lines, namely macrophages (RAW 264.7), which are the first line of defense of the human body against intruding pathogens; endothelial cells (HUVEC), which are the cells lining our blood vessels; and a model cancer cell line (HeLa). Since it is well known that blood flow generates shear stress on the surface of endothelial cells as well as to the circulating macrophages, we evaluated the cellular uptake of $\mathrm{MG} / \mathrm{L}^{\mathrm{F}} / \mathrm{PDA}$ and PEGylated $\mathrm{MG} / \mathrm{L}^{\mathrm{F}} / \mathrm{PDA} / \mathrm{PEG}$ multicompartment carriers by HUVEC and RAW 264.7 cells under microvasculature shear stress conditions (i.e., $\tau 0.5$ and t4)[13] by monitoring both the cell mean fluorescence intensity (CMFI) and the CUE. 
We first determined the maximum amount of MG/L/PDA that could be administered to the cells without causing a detrimental effect as well as the incubation time that promoted the highest cellular uptake (for details see Supplementary Material, Fig. S5).

RAW 264.7 cells. Fig. 5a shows an increase in CMFI and CUE for both MG/L ${ }^{\mathrm{F}} / \mathrm{PDA}$ and $\mathrm{MG} / \mathrm{L}^{\mathrm{F}} / \mathrm{PDA} / \mathrm{PEG}$ carriers upon applying shear stress. This increase, which is most pronounced at $\tau 0.5$ and it is almost negligible for $\mathrm{MG} / \mathrm{L}^{\mathrm{F}} / \mathrm{PDA}$ carriers at $\tau 4$, indicates a higher uptake/association of the carriers with the RAW 264.7 cells in the presence of shear stress. Additionally, a decrease in CMFI upon PEGylation can be observed at all the tested conditions. While, at $\tau 4$, the decrease in CMFI is not statistically significant, a very pronounced CMFI decrease is observed at both $\tau 0$ and $\tau 0.5$ ( 2.5 and $\sim 1.7$ fold decrease, respectively). Those results confirm the functionalization of the carriers surface while demonstrating that the physiological dynamics highly influence the cell/carrier interaction in this cell line. 

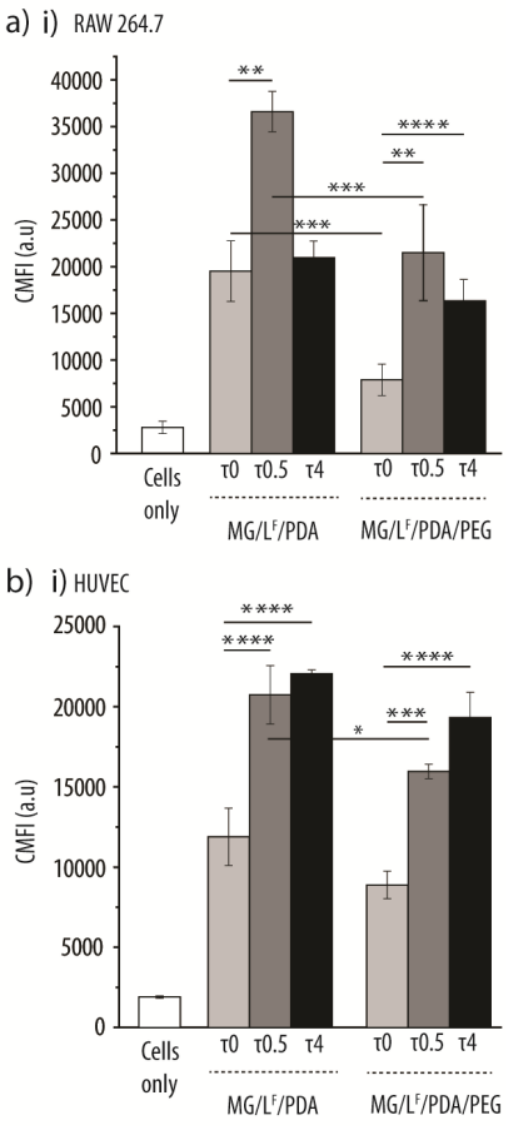

c) i) HeLa

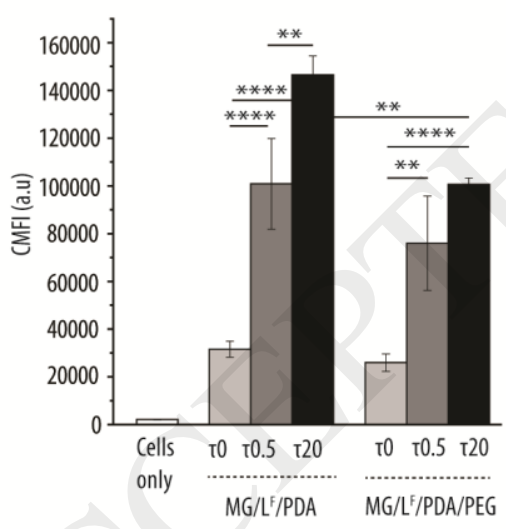

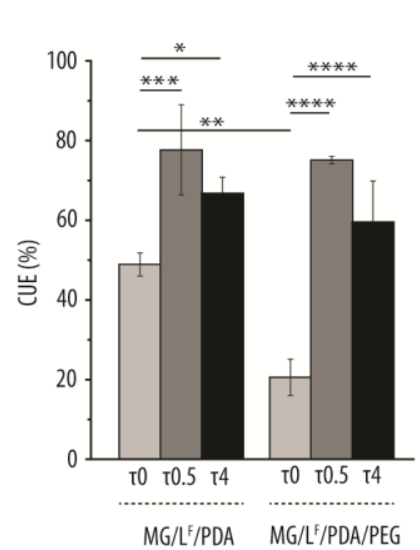

i)

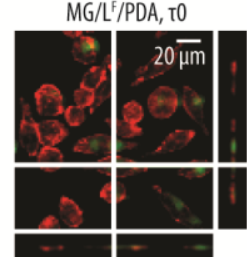

$\mathrm{MG} / \mathrm{L}^{\mathrm{F} / \mathrm{PDA}, \mathrm{T} 4}$

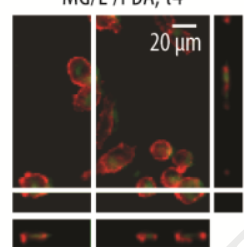

ii)
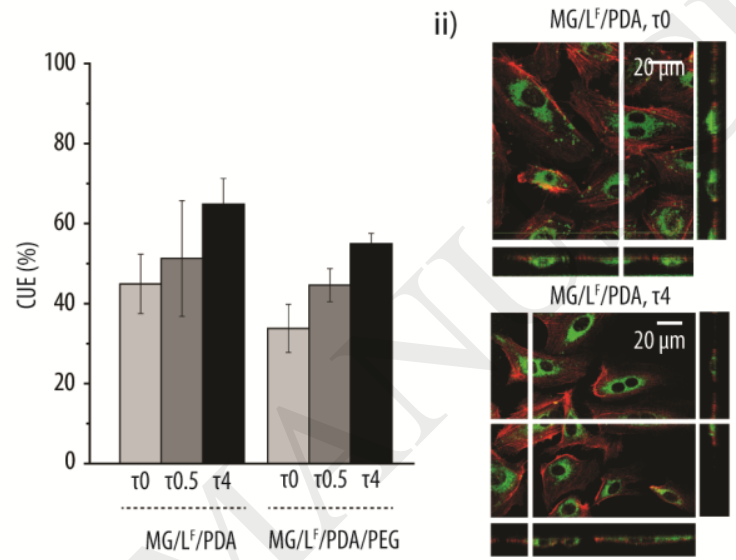

ii)

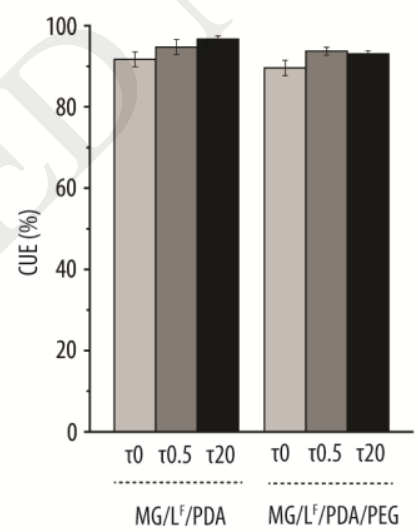

$M G / L^{E} / P D A / P E G, T O$

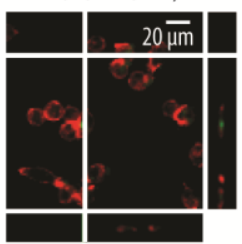

$\mathrm{MG} / \mathrm{L}^{\mathrm{F}} / \mathrm{PDA} / \mathrm{PEG}, \mathrm{T} 4$

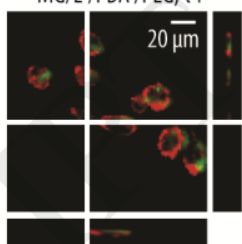

$\mathrm{MG} / \mathrm{L}^{\mathrm{F}} / \mathrm{PDA} / \mathrm{PEG}, \mathrm{TO}$

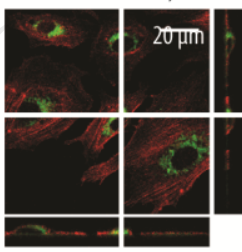

$\mathrm{MG} / \mathrm{L} / \mathrm{PDA} / \mathrm{PEG}, \mathrm{TA}$
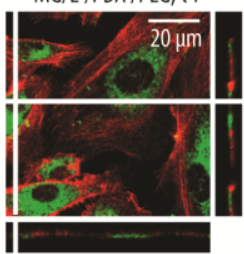

$M G / L / P D A / P E G, T 0$

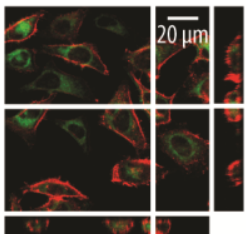

$\mathrm{MG} / \mathrm{L} / \mathrm{PDA} / \mathrm{PEG}, \mathrm{T} 20$

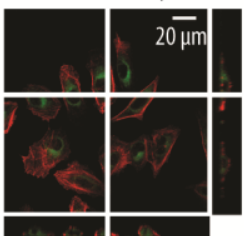

Fig.5. i) Cell mean fluorescence intensity (CMFI) and cell uptake efficiency (CUE) of RAW 264.7 (macrophages) (a) HUVEC (endothelial) (b) and HeLa (cervix cancer) (c) cells upon exposure to either non-PEGylated (MG/L ${ }^{\mathrm{F}} / \mathrm{PDA}$ ) or PEGylated (MG/L $\mathrm{L}^{\mathrm{F}} / \mathrm{PDA} / \mathrm{PEG}$ ) carriers at $\tau$

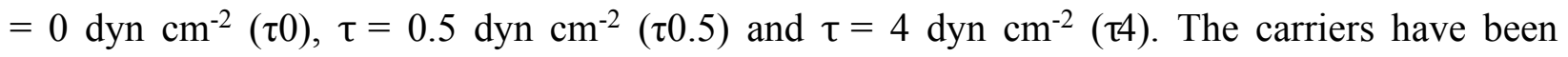
assembled with fluorescently labelled liposomes $\left(\mathrm{L}^{\mathrm{F}}\right)$. At least three independent experiments were carried out $(\mathrm{n}=3),{ }^{*} \mathrm{p} \leq 0.05 ; * * \mathrm{p} \leq 0.01 ; * * * \mathrm{p} \leq 0.001 ; * * * * \mathrm{p} \leq 0.0001$. ii) Confocal laser scanning microscopy images showing the internalization of the carriers by RAW 264.7 (a) 
HUVEC (b) and HeLa (c) cells at different shear stress conditions. The actin filaments of the cells have been stained with phalloidin-TRITC (red fluorescence signal) while the green fluorescence signal is due to the fluorescently labelled liposomes $\left(\mathrm{L}^{\mathrm{F}}\right)$ embedded within both non-PEGylated (MG/L $\left.\mathrm{F}^{\mathrm{F}} / \mathrm{PDA}\right)$ and PEGylated $\left(\mathrm{MG} / \mathrm{L}^{\mathrm{F}} / \mathrm{PDA} / \mathrm{PEG}\right)$ carriers.

To verify that the multicompartment carriers had been internalized by the cells, the macrophages exposed to the carriers were fixed, their membranes stained and visualized by CLSM. Fig. 5ai (and Fig. S6a) depict representative CLSM images confirming the internalization of the carriers at all the studied conditions as shown by the green fluorescence signal arising from the $\mathrm{L}^{\mathrm{F}}$ while the actin filaments of the cells have been stained with phalloidin-TRITC (red fluorescence signal). The insets, which depict the projection of the slides in the z-axis, further corroborate the internalization of the carriers.

HUVEC cells. Fig. 5bi shows how, upon applying shear stress, there is an overall increase in CMFI for both $\mathrm{MG} / \mathrm{L}^{\mathrm{F}} / \mathrm{PDA}$ and $\mathrm{MG} / \mathrm{L}^{\mathrm{F}} / \mathrm{PDA} / \mathrm{PEG}$ carriers. In contrast to RAW 264.7 cells where the highest CMFI was observed at $\tau 0.5$, for HUVEC, the higher the shear stress, the higher the CMFI. Although far less pronounced, an increase in CUE is also observed upon applying shear stress for all the tested conditions. As with the RAW 264.7 cells, PEGylation of the carrier also results in a decrease of CMFI and CUE for all the tested conditions. However, a significant decrease in CMFI was only observed at $\tau 0.5$, and this decrease was far less pronounced than for RAW 264.7 cells. It is also worth noticing that, for HUVEC cells, the CUE values are relatively low as compared to the CUE values for macrophages, reaching a maximum of only $\sim 65 \%$ for the non-PEGylated carriers at $\tau 4$. Internalization of the carriers by HUVEC cells was also confirmed by CLSM (Fig. 5bii and Fig. S6b). 
HeLa cells. While the effect of shear stress on endothelial cells and macrophages has been extensively investigated,[13] studies on the effect of shear stress on tumor cells remain scarce. However, cancer cells experience shear stress produced by both the blood flow in the vascular microenvironment (0.5-30.0 dyn $\mathrm{cm}^{-2}$ ) and the interstitial flow (with values as low as $0.1 \mathrm{dyn}^{-}$ ${ }^{2}$ ).[26,27] Hence, we studied the cellular uptake of MG/L ${ }^{\mathrm{F}} / \mathrm{PDA}$ and MG/L $/ \mathrm{PDA} / \mathrm{PEG}$ by HeLa cells at $\tau 0$ and at two physiologically relevant shear stresses $(\tau 0.5$ and $\tau 20)$. The results, depicted in Fig. 5ci, show how the exposure of HeLa cells to the carriers at both $\tau 0.5$ and $\tau 20$ leads to a dramatic increase in CMFI. In contrast, no significant increase in CUE was observed upon applying shear stress, indicating saturation of the cells by the carriers at $\tau 0$. While no PEGylation effect was observed at $\tau 0$ and $\tau 0.5$, a pronounced decrease in CMFI was observed at 220. CLSM images also show the successful internalization of the carriers by the HeLa cells (Fig. 5cii and Fig. S6c). It is worth noticing that the CMFI of HeLa at all the studied conditions was much higher as compared to the CMFI of RAW 264.7 and HUVEC cells, suggesting that the reported multicompartment carrier is preferentially internalized by HeLa cells.

To the best of our knowledge, these results represent one of the first reports on the influence of shear stress on the PEGylation efficiency in a cancer cell line and, although more in depth studies are required to understand the underlying mechanism, they reveal the important role that shear stress plays on the cellular uptake of different carriers, in particular for cancer cells.

\section{Cell viability}

We next assessed the cell viability of the three cell lines exposed to MG/L/PDA and MG/L/PDA/PEG carriers at the highest applied shear stress. Fig. 6 shows a significant decrease in cell viability only for RAW 264.7 cells exposed to both type of carriers at $\tau 4$. These results can 
be explained by the semi-adherent nature of RAW264.7, which can lead to cell-detachment upon exposure to shear stress.

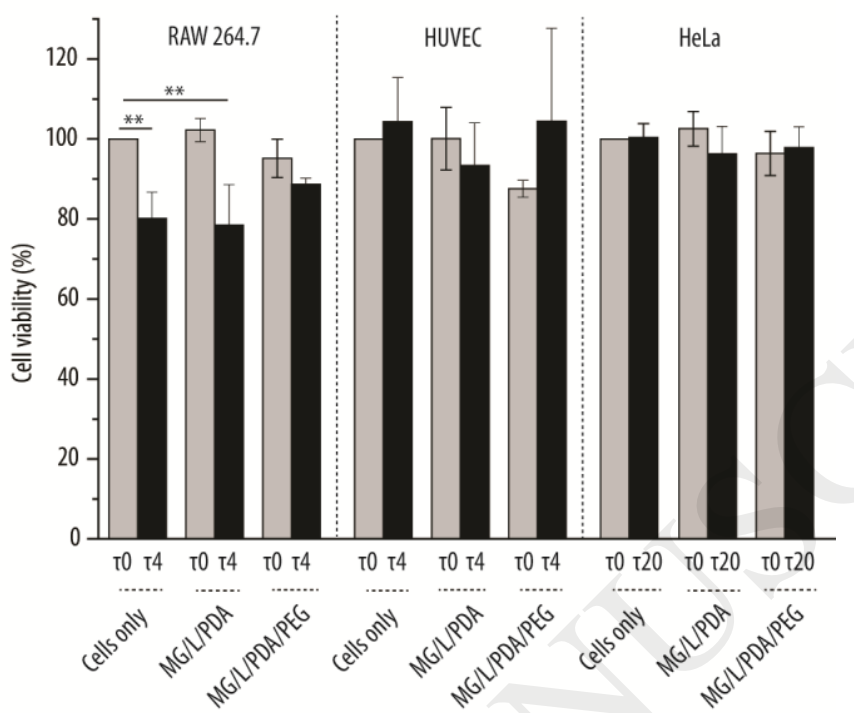

Fig.6. Normalized cell viability readings of RAW 264.7 (macrophages), HUVEC (endothelial) and HeLa (cervix cancer) cells upon exposure to either non-PEGylated (MG/L/PDA) or PEGylated (MG/L/PDA/PEG) carriers in static $\left(\tau=0\right.$ dyn $\left.\mathrm{cm}^{-2}, \tau 0\right)$ and two different shear stress

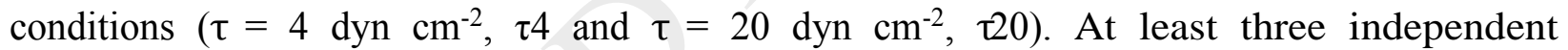
experiments were carried out $(\mathrm{n}=3), * * \mathrm{p} \leq 0.01$.

\section{Cellular uptake pathway}

Since the cell internalization pathway will determine the intracellular fate of the carriers, we elucidated the cell entry pathways for both $\mathrm{MG} / \mathrm{L}^{\mathrm{F}} / \mathrm{PDA}$ and $\mathrm{MG} / \mathrm{L}^{\mathrm{F}} / \mathrm{PDA} / \mathrm{PEG}$ for each cell line at static and shear stress conditions.

The carriers uptake by RAW 264.7 cells was assessed in the presence of filipin, amiloride and lantruculin A which inhibit caveolae-mediated endocytosis (CvME), macropinocytosis and phagocytosis, respectively. The carriers uptake by HUVEC and HeLa cells was investigated in the presence of filipin, amiloride and chlorpromazine which is known to inhibit the clathrin- 
mediated endocytosis (CME).[28] The internalization pathway in HUVEC and HeLa cells was not evaluated in the presence of latrunculin A due to the non-phagocytic nature of both cell lines. The shear stress condition with the largest effect on both the CMFI and the PEGylation effect on each cell line was the one selected to resolve the carriers cell internalization pathway. Preservation of cell viability for the different cell lines in the presence of the inhibitors is shown in Fig. S6. Fig. 7 shows the CMFI readings for the three different cell lines, which have been normalized to the $\mathrm{CMFI}$ of $\mathrm{MG} / \mathrm{L}^{\mathrm{F}} / \mathrm{PDA}$ or $\mathrm{MG} / \mathrm{L}^{\mathrm{F}} / \mathrm{PDA} / \mathrm{PEG}$ incubated with cells in the absence of inhibitors. As expected for a macrophage cell line, the internalization of both carriers was most efficiently inhibited by latrunculin A at both $\tau 0$ and $\tau 0.5$ (Fig. 7a). Interestingly, at $\tau 0.5$, the nCMFI of cells exposed to $\mathrm{MG} / \mathrm{L}^{\mathrm{F}} / \mathrm{PDA}$ was also significantly reduced by both filipin and amiloride, suggesting that shear stress activates CvME and macropinocytosis. For HUVEC cells, as shown in Fig. 7b, at $\tau 0$ the uptake of non-PEGylated carriers was inhibited by both filipin and amiloride at $\tau 0$, suggesting that the carriers are preferentially internalized trough CvME and macropinocytosis. However, the results were different for non-PEGylated carriers at $\tau 0.5$ or PEGylated carriers at $\tau 0$ and $\tau 0.5$ and no significant decrease in nCMFI was observed for any of the tested inhibitors. Interestingly, when exposing HUVEC cells to the PEGylated carriers at $\tau 0$ in the presence of chlorpromazine, a $\sim 40 \%$ increase in nCMFI was observed, suggesting that the inhibition of a specific route can lead to the activation of other uptake mechanisms. 


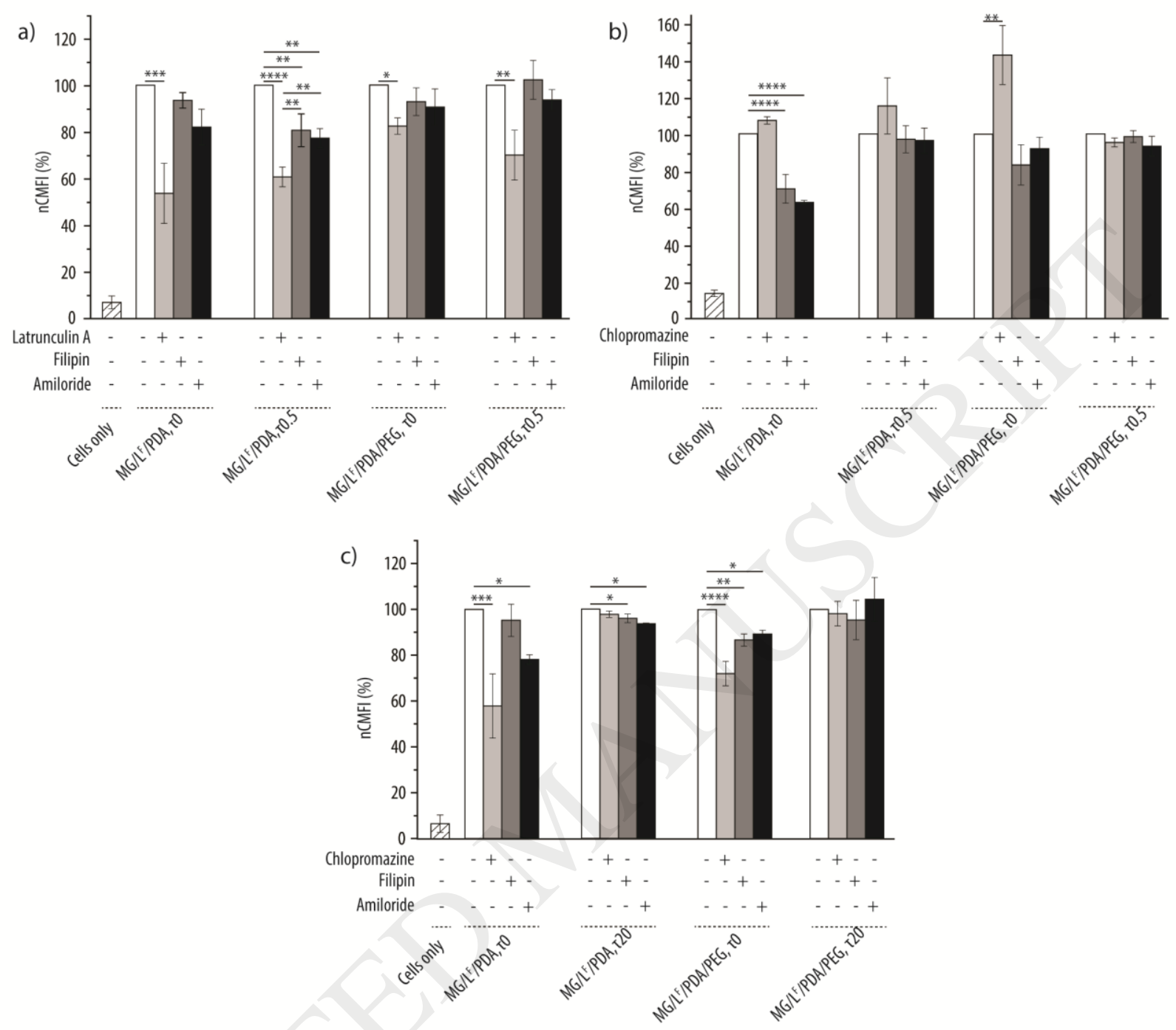

Fig.7. Normalized cell mean fluorescence intensity (nCMFI) readings of a) RAW 264.7 (macrophages), b) HUVEC (endothelial) and c) HeLa (cervix cancer) cells upon exposure to either non-PEGylated (MG/L $/$ $/ P D A)$ or PEGylated $\left(\mathrm{MG} / \mathrm{L}^{\mathrm{F}} / \mathrm{PDA} / \mathrm{PEG}\right)$ carriers in the presence of chemical inhibitors in static $\left(\tau=0\right.$ dyn $\left.\mathrm{cm}^{-2}, \tau 0\right)$ and two different shear stress conditions $(\tau=$

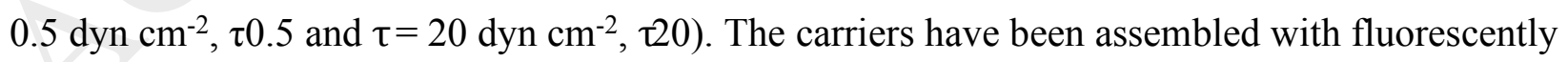
labelled liposomes $\left(\mathrm{L}^{\mathrm{F}}\right)$. At least three independent experiments were carried out $(\mathrm{n}=3),{ }^{*} \mathrm{p}$ $\leq 0.05 ; * * \mathrm{p} \leq 0.01 ; * * * \mathrm{p} \leq 0.001 ; * * * * \mathrm{p} \leq 0.0001$. 
For HeLa cells, Fig. 7c shows how, at $\tau 0$, incubation with chlorpromazine with both nonPEGylated and PEGylated carriers resulted in a pronounced decrease in nCMFI. Filipin and amiloride, to a lesser extent, also reduced the nCMFI suggesting that both carriers are preferentially internalized by $\mathrm{CME}$ followed by $\mathrm{CvME}$ and macropinocytosis. However, this effect is lost at 20 . While no decrease in nCMFI was observed for PEGylated carriers, only a significant slight decrease in nCMFI was observed for non-PEGylated carriers incubated with filipin and amiloride. These results highlight that, for HeLa cells, while PEGylation has barely any effect on the cell internalization pathway, the presence of shear stress has a dramatic effect by inhibiting the main internalization route at $\tau 0$ (i.e., CME). All in all, these results highlight how both the presence of shear stress as well as the surface coating of the carrier can activate or inhibit (several) cell internalization mechanisms.

\section{CONCLUSIONS}

We have reported the development of a novel multicompartment carrier that takes advantage of the different nature of its constituting components, namely liposomes and polymeric microgels. With this novel multicompartment carrier, different release profiles for different model compounds are achieved while ensuring their co-localization at the target site. We have shown that PEGylation of the carriers surface resulted in protection against protein adsorption regardless of the presence of or absence of shear stress. Additionally, diminished cellular uptake was observed for the three studied cell lines (RAW 264.7, HUVEC and HeLa cells). The designed carrier is preferentially internalized by HeLa cells both in the presence and absence of shear stress making it promising for antitumor delivery. Importantly, absence of inherent toxicity of the multicompartment carrier was found in all the tested conditions, thus evidencing good biocompatibility. Lastly, the influence of shear stress was clearly demonstrated in terms of cell 
mean fluorescence intensity, cellular uptake efficiency and internalization pathways. For the three investigated cell lines, the internalization of the carrier was successfully confirmed.

Taken together, our results clearly demonstrate that shear stress should be considered when characterizing novel drug delivery platforms in in vitro set-ups prior moving to in vivo studies.

\section{ACKNOWLEDGEMENTS}

This work has been supported by the Lundbeck Foundation, Denmark [Grant No. R163-2013$15402]$.

\section{COMPETING INTERESTS}

The authors do not have competing interests to declare.

\section{REFERENCES}

[1] M.J. York-Duran, M. Godoy-Gallardo, C. Labay, A.J. Urquhart, T.L. Andresen, L. HostaRigau, Recent advances in compartmentalized synthetic architectures as drug carriers, cell mimics and artificial organelles, Colloids Surf., B. 152 (2017) 199-213. doi:10.1016/j.colsurfb.2017.01.014.

[2] M. Marguet, C. Bonduelle, S. Lecommandoux, Multicompartmentalized polymeric systems: towards biomimetic cellular structure and function, Chem. Soc. Rev. 42 (2013) 512-529. doi:10.1039/C2CS35312A.

[3] M. Godoy-Gallardo, M.J. York-Duran, L. Hosta-Rigau, Recent progress in micro/nanoreactors toward the creation of artificial organelles, Adv. Healthc. Mater. 7 (2018) 1-35. doi:10.1002/adhm.201700917.

[4] N.-N. Deng, M. Yelleswarapu, L. Zheng, W.T.S. Huck, Microfluidic assembly of 
monodisperse vesosomes as artificial cell models, J. Am. Chem. Soc. 139 (2017) 587590. doi:10.1021/jacs.6b10977.

[5] X. Liu, P. Formanek, B. Voit, D. Appelhans, Functional Cellular Mimics for the Spatiotemporal Control of Multiple Enzymatic Cascade Reactions, Angew. Chem., Int. Ed. 56 (2017) 16233-16238. doi:10.1002/anie.201708826.

[6] M. Godoy-Gallardo, C. Labay, M.M.T. Jansman, P.K. Ek, L. Hosta-Rigau, Intracellular microreactors as artificial organelles to conduct multiple enzymatic reactions simultaneously, Adv. Healthc. Mater. 6 (2017) 1-14. doi:10.1002/adhm.201601190.

[7] J. Gan, X. Guan, J. Zheng, H. Guo, K. Wu, L. Liang, M. Lu, Biodegradable, thermoresponsive PNIPAM-based hydrogel scaffolds for the sustained release of levofloxacin, RSC Adv. 6 (2016) 32967-32978. doi:10.1039/C6RA03045A.

[8] Q. Saleem, Z. Zhang, C.C. Gradinaru, P.M. Macdonald, Liposome-coated hydrogel spheres: delivery vehicles with tandem release from distinct compartments, Langmuir. 29 (2013) 14603-14612. doi:10.1021/la402796k.

[9] L. Hosta-Rigau, P. Schattling, B.M. Teo, M.E. Lynge, B. Städler, Recent progress of liposomes in nanomedicine, J. Mater. Chem. B. 2 (2014) 6686-6691. doi:10.1039/C4TB00825A.

[10] B.M. Teo, L. Hosta-Rigau, M.E. Lynge, B. Städler, Liposome-containing polymer films and colloidal assemblies towards biomedical applications, Nanoscale. 6 (2014) 64266433. doi:10.1039/c4nr00459k.

[11] B.M. Teo, R. Van Der Westen, L. Hosta-Rigau, B. Städler, Cell response to PEGylated poly(dopamine) coated liposomes considering shear stress, Biochim. Biophys. Acta - Gen. Subj. 1830 (2013) 4838-4847. doi:10.1016/j.bbagen.2013.06.022. 
[12] J.S. Suk, Q. Xu, N. Kim, J. Hanes, L.M. Ensign, PEGylation as a strategy for improving nanoparticle-based drug and gene delivery, Adv. Drug Deliv. Rev. 99 (2016) $28-51$. doi:10.1016/j.addr.2015.09.012.

[13] M. Godoy-Gallardo, P.K. Ek, M.M.T. Jansman, B.M. Wohl, L. Hosta-Rigau, Interaction between drug delivery vehicles and cells under the effect of shear stress, Biomicrofluidics. 9 (2015) 1-19. doi:10.1063/1.4923324.

[14] L. Hosta-Rigau, B. Städler, Shear stress and its effect on the interaction of myoblast cells with nanosized drug delivery vehicles, Mol. Pharm. 10 (2013) 2707-2712. doi:10.1021/mp4001298.

[15] J. Cui, M. Björnmalm, K. Liang, C. Xu, J.P. Best, X. Zhang, F. Caruso, Super-soft hydrogel particles with tunable elasticity in a microfluidic blood capillary model, Adv. Mater. 26 (2014) 7295-7299. doi:10.1002/adma.201402753.

[16] M. Björnmalm, Y. Yan, F. Caruso, Engineering and evaluating drug delivery particles in microfluidic devices, J. Controlled Release. $190 \quad$ (2014) 139-149. doi:10.1016/j.jconrel.2014.04.030.

[17] A. Albanese, A.K. Lam, E.A. Sykes, J. V. Rocheleau, W.C.W. Chan, Tumour-on-a-chip provides an optical window into nanoparticle tissue transport, Nat. Commun. 4 (2013) 2718. doi:10.1038/ncomms3718.

[18] M. Godoy-Gallardo, C. Labay, V.D. Trikalitis, P.J. Kempen, J.B. Larsen, T.L. Andresen, L. Hosta-Rigau, Multicompartment artificial organelles conducting enzymatic cascade reactions inside cells, ACS Appl. Mater. Interfaces. 9 (2017) 15907-15921. doi:10.1021/acsami.6b16275.

[19] J. Yang, M.A. Cohen Stuart, M. Kamperman, Jack of all trades: versatile catechol 
crosslinking mechanisms, Chem. Soc. Rev. 43 (2014) 8271-8298. doi:10.1039/C4CS00185K.

[20] Y. Jing, H. Trefna, M. Persson, B. Kasemo, S. Svedhem, Formation of supported lipid bilayers on silica: relation to lipid phase transition temperature and liposome size., Soft Matter. 10 (2014) 187-195. doi:10.1039/c3sm50947h.

[21] N. Bertrand, J.C. Leroux, The journey of a drug-carrier in the body: An anatomophysiological perspective, J. Control. Release. 161 (2012) 152-163. doi:10.1016/j.jconrel.2011.09.098.

[22] R. van der Westen, L. Hosta-Rigau, D.S. Sutherland, K.N. Goldie, F. Albericio, A. Postma, B. Städler, Myoblast cell interaction with polydopamine coated liposomes, Biointerphases. 7 (2012) 1-9. doi:10.1007/s13758-011-0008-4.

[23] N. MacKinnon, G. Guérin, B. Liu, C.C. Gradinaru, J.L. Rubinstein, P.M. Macdonald, Triggered instability of liposomes bound to hydrophobically modified core-shell PNIPAM hydrogel beads, Langmuir. 26 (2010) 1081-1089. doi:10.1021/la902423v.

[24] E.S. Jeong, H.A. Son, M.K. Kim, K.-H. Park, S. Kay, P.S. Chae, J.W. Kim, Fabrication of monodisperse liposomes-in-microgel hybrid microparticles in capillary-based microfluidic devices, Colloids Surf., B. 123 (2014) 339-344. doi:10.1016/j.colsurfb.2014.09.039.

[25] R. Thakur, A. Das, A. Chakraborty, Interaction of human serum albumin with liposomes of saturated and unsaturated lipids with different phase transition temperatures: A spectroscopic investigation by membrane probe PRODAN, RSC Adv. 4 (2014) 1433514347. doi:10.1039/c4ra01214c.

[26] F. Michor, J. Liphardt, M. Ferrari, J. Widom, What does physics have to do with cancer?, Nat. Rev. Cancer. 11 (2011) 657-670. doi:10.1002/nbm.3066. 
[27] M.A. Swartz, A.W. Lund, Lymphatic and interstitial flow in the tumour microenvironment: Linking mechanobiology with immunity, Nat. Rev. Cancer. 12 (2012) 210-219. doi:10.1038/nrc3186.

[28] H. Hillaireau, P. Couvreur, Nanocarriers' entry into the cell: Relevance to drug delivery, Cell. Mol. Life Sci. 66 (2009) 2873-2896. doi:10.1007/s00018-009-0053-Z. 